\title{
IDENTIFIKASI PEMANFAATAN LINGKUNGAN SEKOLAH SEBAGAI SUMBER BELAJAR DALAM KEGIATAN OUT BOND
}

\author{
Yudabbirul Arif \\ Universitas Nusa Cendana \\ email: yudabbirul@staf.undana.ac.id
}

\begin{abstract}
Abstrak
Didalam proses pembelajaran out bond dalam pemanfaatan fasilitasnya belum maksimal sehingga membuat siswa sering kurang bersemangat dan tidak maksimal sehingga akan berdampak kepada pemahaman siswa itu sendiri. Pembelajaran harus dilaksanakan maksimal dengan pemanfaatan lingkungan sehingga siswa mempunyai gerak motorik yang luas dan bagus. Jenis penelitian ini adalah deskriptif dengan menggunakan pendekatan kualitatif naturalistic yang berupaya untuk mendapatkan faktorfaktor secara alami dengan inteprestasi yang tepat dengan tujuan deskripsi atau gambaran secara komprehensif akurat . Subyek pada penelitian ini adalah siswa-siswi kelas VIII C dan kelas VIII D SMP Negeri 4 Golewa yang berjumlah 47 orang. Penelitian ini merupakan penelitian mata pelajaran ekstra yang di lakukan di lingkungan sekolah, dan di tempat rekreasi dengan tujuan menanamkan nilai-nilai,melestarikan wilayah yang memiliki keindahan alam. Hasil penelitian ini menunjukkan bahwa proses pembelajaran Out Bond dapat membuat siswa lebih aktif, cerdas dan kreatif dalam pembelajaran penjas dengan memanfaatkan lingkungan sekolah sebagai sumber belajar. Kesimpulan bahwa kegiatan out bond di SMP Negeri 4 Golewa dengan melakukan pemanfaatan lingkungan sekolah dalam kegiatan out bond sangat bagus terhadap siswa.
\end{abstract}

Kata Kunci :, lingkungan sekolah, Out Bond

\begin{abstract}
In the out bond learning process, the utilization of the facilities has not been maximal so that it makes students often less enthusiastic and not maximal so that it will have an impact on students' understanding. Learning must be carried out maximally by utilizing the environment so that students have wide and good motor movements. This type of research is descriptive using a naturalistic qualitative approach that seeks to get the factors naturally with the right interpretation with the aim of a comprehensive, accurate description or description. The subjects in this study were 47 students of class VIII C and class VIII D of SMP Negeri 4 Golewa. This research is an extra subject research conducted in a school environment and in a recreation area with the aim of instilling values and preserving areas that have natural beauty. The results of this study indicate that the Out Bond learning process can make students more active, intelligent and creative in Physical Education learning by utilizing the school environment as a learning resource. The conclusion is that out bond activities at SMP Negeri 4 Golewa by utilizing the school environment in out bond activities are very good for students.
\end{abstract}

Keywords: school environment, Out Bond, 


\section{PENDAHULUAN}

Pendidikan jasmani memberikan kesempatan pada siswa untuk terlibat langsung dalam aneka pengelaman belajar melalui aktivitas jasmani, bermain dan berolahraga yang dilakukan secara sistematis, terarah dan terencana pembekalan pengalaman belajar itu diarahkan untuk membina sekaligus membentuk gaya hidup yang aktif sepanjang hayat. Throughout Building Character, Community, and a Growth Mindset in Physical Education, you will find previews of activity materials that can be found in the web resource (Anderson \& Glover, 2017). Seperti yang dikatakan bahwa untuk membangun karakter, dan pola pikir yang bagus terdapat didalam pembelajaran pendidikan jasmani, serta banyak contoh nyatanya didalam lingkungan sekolah maupun didalam lingkungan masyarakat. Semua itu dapat ditemukan di berbagai sumber lansung maupun tidak lansung.

Lingkungan sekolah merupakan faktor utama yang harus ada dalam pelaksanaan kegiatan outbond, tanpa adanya lingkungan sekolah yang memadai maka kegiatan out bond tidak akan bisa berjalan dengan baik. Pemanfaatan lingkungan sekolah dalam pelaksanaan kegiatan out bond di SMP Negeri 4 Golewa Kabupaten Ngada belum dilakukan secara maksimal sehingga siswa sering kali merasa jenuh untuk melakukan kegiatan tersebut. Perkembangan motorik anak di dasari oleh banyaknya aktifitas kebugaran jasmani yang dilakukan. Pelaksanaan kegiatan out bond yang bagus tentunya akan berpengaruh terhadap perkembangan motorik siswa untuk kedepannya sehingga kemampuan fisik dan mental siswa akan semakin bagus. can one expect a completely safe environment with no risk to personal safety (Swickard, 2016). Dalam artianya bahwa setiap anak dapat mengharapkan lingkungan yang sepenuhnya aman tanpa risiko terhadap keselamatan pribadi. Setiap anak haruslah bisa menjaga diri sendiri sehingga bisa mandiri dan bertanggung jawab, maka akan bisa berdampak terhadap perubahan dirinya.

Partisipasi siswa di kegiatan outbond kurang memberikan respon karna banyak dari siswa yang kurang bersemangat dalam melakukan kegiatan, bagaimana cara kita untuk bisa membuat para peserta didik bisa antusias dalam melaksanakan kegiatan tersebut bisa kita manfaatkan secara maksimal lingkungan sekolah. Nantinya, jika siswa sudah antusias maka siswa akan mulai bergerak secara lues dan semangat sehingga akan membentuk fisik anak dan mental yang bagus, serta pemahaman tentang nilainilai outbond itu sendiri.

Physical education is usually imparted during primary and secondary schooling. It is an educational practice aimed at enhancing psychomotor learning and health (Harrison, 2017). Seperti yang dikatakan bahwa pendidikan jasmani wajib diberikan selama sekolah dasar dan menengah. Salah satunya bisa dengan menggunakan metode bermain agar pendidikan jasmani bisa terleksana dengan efektif dengan melakukan pemanfaatan lingkungan seperti out bond.

Out bond merupakan suatu bentuk dari pembelajaran segala ilmu terapan yang disulasikan dan dilakukan di alam terbuka atau tertutup dengan bentuk permainan yang efektif, yang menggabungkan antara intelegensia, fisik dan mental. Exercise capacity in children and the activities in which they can successfully engage change in a predictable way across development periods (Kohl \& Cook, 2013). Dikatakan bahwa Kapasitas latihan pada anak-anak dan aktivitas di mana mereka dapat berhasil melakukan perubahan dengan cara yang dapat diprediksi di seluruh periode perkembangan. Dalam artian lain atau dari sumber yang lain out bond merupakan kegiatan di alam terbuka. 
Oleh karena itu bermain merupakan fitrah yang dialami setiap anak. She found that children have their own logic at each stage of development, along with certain preferred activities and natural tendencies in behavior (Seldin, 2019). Dia menemukan anakanak memiliki logika mereka sendiri di setiap tahap perkembangan, bersama dengan aktivitas pilihan tertentu dan kecenderungan alami dalam perilaku.

This emphasis on words and their impact on learning enrich children's physical literacy greatly (Clements \& Schneider, 2017). Seperti yang dikatakan bahwa penekanan pada kata-kata yang jelas dan memiliki intonasi yang baik maka pengaruhnya terhadap pembelajaran sangat memperkaya literasi fisik anak-anak. Mereka akan memperoleh pengalaman yang merupakan guru dalam proses pembelajaran secara alami. Hal itu dalam rangka menambah dan mengembangkan pengetahuan dari setiap pengalamannya. The prevalence and health impacts of physical inactivity, together with evidence indicating its susceptibility to change, have resulted in calls for action aimed at increasing physical activity across the life span. Clearly, the earlier in life this important health behavior can be ingrained, the greater the impact will be on life-long health (Kohl \& Cook, 2013). Seperti yang dikatakan bahwa prevalensi dan dampak kesehatan dari ketidak aktifan fisik, bersama dengan bukti yang menunjukkan kerentanannya terhadap perubahan, telah menghasilkan seruan untuk tindakan yang ditujukan untuk meningkatkan aktivitas fisik sepanjang masa hidup.

Molecular and cellular underpinnings of muscle growth, repair and preservation are discussed with reference to how they may influence physical performance (Arif, 2019).. Maka dapat disimpulkan menurut kutipan diatas, bahwa pertumbuhan, perbaikan, dan pelestarian kemampuan motorik anak memerlukan fisik yang bagus sehingga didalam melaksanakan pembelajaran maka anak akan lebih fokus dan memberikan dampak yang baik. New studies seeking to identify factors that influence the development of classes, as well as the determinants of physical activity practice of students in PE classes, should be performed (Costa, 2017). Dapat dipahami bahwa ini merupakan studi baru yang berusaha mengidentifikasi faktor-faktor yang mempengaruhi perkembangan kelas, serta penentu praktik aktivitas fisik siswa di kelas olahraga, harus dilakukan untuk meningkatkan kemampuan motorik anak salah satunya dengan cara outbond di lingkungan sekolah.

Berdasarkan perkembangan ilmu dan teknologi, pada zaman ini diharapkan kepada seluruh insan masyarakat pendidik/ pelatih yang nantinya mampu memberikan suatu perubahan baru agar dapat meningkatkan perkembangan prestasi, baik dalam disiplin ilmu pendidikan maupun prestasi olahraga (Arif et al., 2019). Sebagaimana yang dijelaskan bahwa seorang guru harus bisa melakukan perubahan baru serta bisa memdofikasikan segala sesuatu dengan latihan dan pendidikan jasmani itu sendiri salah satunya dengan pemanfaatan lingkungan sehingga bisa maksimal dalam melaksanakan pendidikan jasmani itu sendiri.

A whole-of-school approach is a multi- component school ini- tiative where all aspects of the school community work collectively together to posi- tively influence the health and wellbeing of children (e.g., active transport, recess, physical education, classroom integration, curriculum, policy, and environmental strategies)(Brewer, 2018). Seperti yang dikatakan bahwa pendekatan sekolah menyeluruh adalah inisiatif sekolah multi-komponen di mana semua aspek komunitas sekolah bekerja sama secara kolektif untuk secara positif mempengaruhi kesehatan 
dan kesejahteraan anak-anak (misalnya, transportasi aktif, istirahat, pendidikan jasmani, integrasi kelas, kurikulum, kebijakan, dan strategi lingkungan).

Prinsip life long education atau belajar seumur hidup menuntut manusia untuk selalu belajar. Dengan kata lain bahwa pada dasarnya masa selama manusia hidup di dunia ini selalu belajar. Proses belajar dapat di dalan rumah (lingkungan informal). Lingkungan I di dalam sekolah (lingkungan formal) lingkungan II maupun lingkungan masyarakat (lingkungan non formal) lingkungan III. Penggunaan media dalam pendidikan sebenarnya sudah sejak lama dilakukan manusia, terutama setelah adanya istilah penyakit verbalisme dalam dunia pendidikan dan pengajaran. Disadari bahwa pengajaran akan lebih berhasil bilamana guru sebanyak dan sedapat mungkin mempergunakan media pendidikan.

\section{METODE}

Dalam penelitian ini menggunakan metode deskriptif dengan menggunakan pendekatan kualitatif naturalistic yang berupaya untuk mendapatkan faKtor-faktor secara alami dengan interprestasi yang tepat dengan tujuan untuk membuat deskripsi atau gambaran secara komprehensif akurat.

Subjek penelitian adalah Siswa SMP Negeri 4 Golewa Kabupaten Ngada. Waktu penelitian berlangsung selama 2 bulan, Tempat penelitian di SMP Negeri 4 Golewa. Peran Dan Informan Penelitian dari kepala sekolah, guru penjas, dan siswa-siswi. Kunci dalam penelitian ini adalah penelitian sendiri dan yang menjadi informan pilihan adalah siswa yang terpilih kelas II dan Guru penjas, Kepala Sekolah. Tujuan adanya informasi pilihan ialah memabantu agar informasi yang tepat pula mengenai situasi dan kondisi batas penelitian.

Data yang dikumpulkan lebih bersifat naturalistic, sehingga peneliti dapat mengambil alternative pemecahan untuk data dengan menggunakan:

a. Observasi merupakan salah satu teknik pengumpulan data yang baik dan mendukung untuk mengumpulkan data yang diperlukan dengan melakukan pengamatan secara langsung atau gejala yang diteliti

b. Interview/Wawancara

Tujuan penelitian menggunakan wawancara dalam penelitian ini adalah agar responden dapat mengemukakan informasi sacara lisan dalam hubungan tatap muka dan informasi yang dikemukakan sesuai informasi yang dibutuhkan.

c. Dokumentasi merupakan teknik pengumpulan data ditujukan kepada subjek penelitian dengan mengumpulkan sejumlah data yang berupa gambar atau foto yang berkaitan dengan masalah penelitian.

Teknik Analisa Data yang dikumpulkan, kemudian dianalisiskan secara kronologis, sistematis dan objektif agar dapat membandingkan hasil wawancara dengan observasi data dalam penelitian ini, selanjutnya diolah sesuai dengan data yang diperoleh dari informasi penelitian.

Instrument yang digunakan Instrument observasi berupa pedoman observasi yang digunakan agar penelitian dapat melakukan pengamatan sesuai dengan tujuan penelitian. Pedoman observasi disusun berdasarkan hasil observasi terhadap pelaku subjek selama observasi. Dalam penelitian ini adapun yang diobservasi oleh peneliti yaitu: Gambaran Lokasi Penelitian \& Kesiapan Sarana, Prasarana.

Instrument Wawancara berupa pedoman wawancara yang digunakan agar wawancara yang dilakukan tidak menyimpang dari tujuan penelitian.

\section{HASIL DAN PEMBAHASAN}

SMP Negeri 4 Golewa berdiri pada tanggal 26 Juni 2004, terletak di 
desa Malanuza, Kecamatan Golewa Tengah, dengan posisi topografis, jarak dengan ibu kota kabupaten Ngada sekitar $17 \mathrm{~km}$, yang mudah di jangkau dengan kendaraan roda dua dan kendaraan roda empat. Lokasi sekolah berada di tengahtengah pemukiman masyarakat, yang mana letaknya berdekatan dengan perguruan tinggi STKIP Citra Bakti Ngada, dan jalan Bajawa-Ende.

Lebih jelas lagi akan diperkuat dengan dena sekolah di bawah ini :

Gambar 1 Denah Sekolah SMP Negeri 4 Golewa

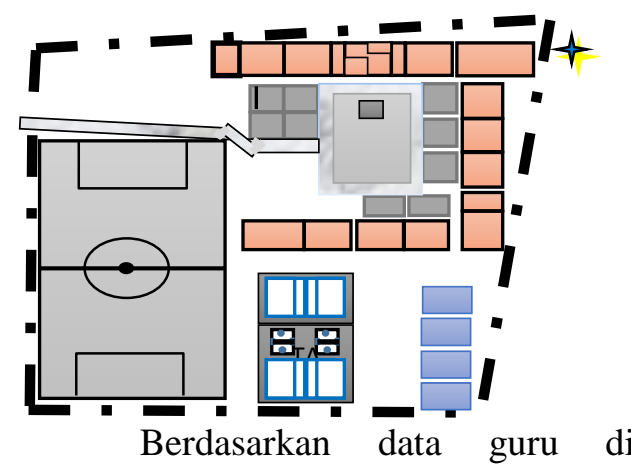
disimpulkan guru berpendidikan S1 dan terdiri dari guru-guru negeri, guru kontrak dan guru honor. Guru-guru tersebut tidak semua berdomisili di wilayah SMP Negeri 4 Golewa tetapi juga ada yang berdomisili di ibu kota kabupaten tepatnya di kota Bajawa, namun kondisi ini sebagai guru tetap melaksanakan kegiatan pembelajaran dan menggunakan kendaraan pribadi maupun kendaraan lainnya.

Staf atau pegawai di lembaga pendidikan ini memiliki peranan yang sangat penting bagi kelancaran urusan di SMP Negeri 4 Golewa dalam hal administrasi, baik itu administrasi. Berdasarkan data siswa disimpulkan siswa yang mengikuti kegiatan pembelajaran di SMP Negeri 4 Golewa yang merupakan siswa yang tinggal di wilayah kecamatan Golewa Tengah, secara jumlah cukup banyak ,karena tingkat kesadaran orang tua murid dan kemampuan siswa terhadap pendidikan sehingga minat terhadap belajar menunjukan kemajuan bagi masyarakat akan pentingnya sekolah.
Hasil observasi kesiapan
saranan dan prasarana olahraga di katakan sangat kurang terbatas, tidak sesuai dengan kebutuhan siswa, namun guru telah mengiasati bersama siswa memodivikasi alat, aturan, tempat, waktu, aturan dan pembelajaran, dan guru PenjaskeRek juga telah melakukan pengembangan model-model pembelajaran berdasarkan kurikulum (K13), dan sarana prasarana untuk mengembangkan permainan Outbond sangatlah menunjang.

Beberapa kegiatan out bond yang dilakukan didalam lingkungan sekolah yaitu:

A. Bergantung di Pohon

Bergantung di pohon merupakan salah satu permainan out bond. Permainan ini sangat mudah dan dapat dilakukan dimana saja, bisa dilakukan di lingkungan sekolah, maupun di lingkungan masyarakat. Kesan yang didapat siswa setelah mengikuti pembelajaran adalah siswa merasa senang dan bahagia. Tujuan dilakukannya pembelajaran ini adalah dimana permainan ini dapat melatih kekuatan otot, konsentrasi, tantangan strategi, dan banyak lagi.

B. Kucing Kejar Ayam

Kucing kejar ayam merupakan salah satu permainan Out bond yang melibatkan banyak siswa/siswi dalam melakukan teknik pembelajaran. Metode pembelajaran ini melibatkan 20 siswa pada kelas VIII C yang terdiri dari 15 orang laki-laki dan 5 orang perempuan. Dari permainan diatas bisa melatih kerja sama kelompok, konsentrasi, kecepatan, kelincahan, dalam kegiatan ini siswa sangat aktif dalam mengikuti proses pembelajaran Out bond

C. Menara Air

Menara air merupakan salah satu permainan Out bond dimana permainan ini siswa tidak boleh menggunakan alat bantu untuk 
menyandar ke tembok atau alat bantu lainnya. Metode pembelajaran ini dilakukan dengan tujuan untuk melatih otot kaki, perut, dan punggung dalam menjaga keseimbangan serta kerjasama tim sehingga wadah tidak jatuh. Dari kelima tim yang melakukan pembelajaran didapat 3 tim yang berhasil menahan wadah dengan baik sedangkan ksedua tim lainnya tidak berhasil.

D. Sendok Bola Estafet

Bola estafet merupakan salah salah satu permainan yang dilakukan menggunakan mulut untuk melatih keseimbangan dan konsentrasi. Kesan yang didapat saat permainan berlangsunng adalah siswa/i sangat aktif dan berkonsentrasi dan saling bekerjasama.

E. Transfer Bola

Transfer bola merupakan salah satu permainan yang bisa membawa banyak tawa. Kesan yang didapat adalah siswa siswi nampak lebih aktif, senang dan energik karena membutuhkan kerjasama tim sehingga lebih ramai dalam melakukan pembelajaran.

F. Permainan Hitam Hijau

Permainan hitam hijau merupakan salah satu permainan yang sangat menyenangkan. Pembelajaran ini sangat seru dilakukan untuk melatih konsentrasi siswa siswi.

G. Memindahkan Karet

Memindahkan karet merupakan salah satu permainan yang dilakukan secara berkelompok dengan memanfaatkan lingkungan sekolah dimana permainan ini menggunakan pulpen dan karet gelang. Kesan yang didapat saat permainan berlangsunng adalah siswa siswi sangat aktif berkonsentrasi dan saling bekerjasama.

H. Memasukan Pulpen Ke dalam Botol Permainan ini melatih konsentrasi dan kesabaran peserta serta bergerak cepat, dalam kehidupan yang nyata tiga komponen tersebut sangat dibutuhkan untuk mencapai suatu target dan tujuan disamping dukungan dari orang-orang di sekitarnya.

Permainan ini sangat aktif diikuti oleh semua tim, yang saling mengadu dukungan kepada peserta utusan masing-masing tim.

I. Tepuk Langkah

Permainan tepuk langkah adalah permainan paling sederhana yang tidak membutuhkan peralatan dan bisa dimainkan kapan saja dan dimana saja. Peserta yang salah menepuk tangan berulang kali ketika pemandu belum melangkahkan kaki secara sempurna dikenakan sangsi oleh peserta lainnya yaitu dengan bergoyang dan peserta lainnya bernyanyi sehingga suasana pembelajaran nampak lebih rileks dan menyenangkan.

J. Memindah Balok Dalam Bentuk Sandal

Permainan ini sangat sederhana, dimana dalam melakukannya diperlukan kecepatan tangan, kaki dan keseimbangan tubuh.

Dari permainan-permainan tersebut diatas, melatih unsur-unsur kerja sama secara kelompok juga secara individu, contohnya seperti dalam unsur kekuatan, unsur kelincahan, unsur keseimbangan, unsur kecepatan, unsur koordinasi dan daya tahan. Analisis kegiatan ini,diambil sampel dari siswa Kelas VIII C dengan jumlah siswa jumlah siswa sebanyak 20 siswa dan Kelas VIII D dengan jumlah siswa jumlah siswa sebanyak 27 siswa dalam kegiatan ini menghasikan kategori baik, dimana kegiatan ini hasil yang diperoleh dari siswa sangat memuaskan bagi peneliti. 


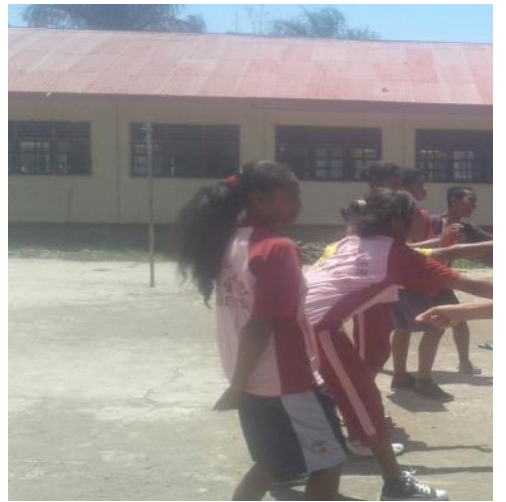

Gambar 2 permainan out bond hitam hijau

Hasil Wawancara Mengenai Proses Pembelajaran OutBond.

Dari ke tiga hasil wawancara dengan ibu kepala sekolah SMP Negeri 4 Golewa, maka dapat disimpulkan bahwa kegiatan pembelajaran penjas yang dilakukan di SMP Negeri 4 Golewa oleh guru penjas berjalan dengan lancar dan menurut pengamatan kepala sekolah antara guru penjas dengan siswa selalu ada kerja sama saat KBM dan guru penjas juga memiliki etos kerja yang tinggi terlihat jelas karena adanya disiplin waktu dan administrasi dalam proses KBM.

Dari ke enam hasil wawancara dengan guru Penjas maka dapat disimpulkan bahwa permainan out bond memanfaatkan lingkungan sekolah sebagai sumber belajar sudah diberikan oleh guru Penjas dan vasilitas yang ada di Sekolah sangat kurang sehingga guru susah mau mengaplikasikan permainanpermainan out bond.

Dari hasil wawancara dengan siswa kelas VIII C SMP Negeri 4 Golewa maka dapat disimpulkan bahwa setiap kegiatan praktek penjas selalu diawali dengan pemanasan lewat pemanasan statis-dinamis, permainan out bond dengan memanfaatkan lingkungan sekolah sebagai sumber belajar.

\section{KESIMPULAN DAN SARAN}

Kesimpulan yang diperoleh adalah proses pembelajaran Out bond dapat membuat siswa lebih aktif, cerdas dan kreatif dalam pembelajaran Penjaskesrek dengan pemanfaatkan lingkungan sekolah sebagai sumber belajar dalam kegiatan Out bond di SMP Negeri 4 Golewa

Untuk saran proses pembelajaran penjas perlu di kembangkan, bukan saja melalui intra tetapi di terapkan melalui kegiatan ekstra pada saat pembelajaran membuat apersepsi yang berkaitan dengan Outbond. Serta Sekolah perlu memfasilitasi alat-alat yang di butuhkan dalam pembelajaran penjaskesrek lebih kususnya fasilitas dalam pembelajaran Outbond.

\section{DAFTAR PUSTAKA}

Anderson, L., \& Glover, D. R. (2017). Building Character, Community, and a Growth Mindset in Physical Education: Activities That Promote Learning and Emotional and Social Development. Human Kinetics.

Arif, Y. (2019). The Effect of Weight Training Using Inner-Load OuterLoad on the Process of Developing Chest Muscles in Fitness Members in the City of Kupang. International Journal of Innovation, Creativity and Change, Volume 5(Issue 3), 478. https://ijicc.net/images/Vol_5_Iss_ 3/28_Neolaka_P478_2019R.pdf

Arif, Y., Boleng, L. M., Babang, V. M. M. F., \& Saba, K. R. (2019).

Pengaruh Keseimbangan, Daya Ledak Otot Tungkai, Dan Motivasi Berprestasi Dengan Kemampuan Tendangan Monthong Doliochagi (Vol. 3, Issue 3). https://doi.org/http://dx.doi.org/10. 23887/ijerr.v2i3.21091.g13182

Brewer, H. (2018). Physical Activity and Health Promotion in the Early Years: Effective Strategies for Early Childhood Educators. In Springer (14th ed.). springer. https://doi.org/10.1007/978-3-31976006-3

Clements, R. L., \& Schneider, S. L. 
(2017). Moving With Words \& Actions Physical Literacy for Preschool and Primary Children. Human Kinetics.

Costa, M. S. (2017). Physical activity patterns in children and adolescents, and the contribution of physical education classes to daily physical activity, according to gender and body mass index. Universidade do Porto.

Harrison, J. (2017). Essentials of Physical Education. White Word Publication.

Kohl, H. W., \& Cook, H. D. (2013). EDUCATING THE STUDENT BODY Taking Physical Activity and Physical Education to School. The national academies press. http://www.nap.edu.

Seldin, T. (2019). How to Raise an Amazing Child The Monstessori Way (Vol. 53, Issue 9). DK. https://doi.org/10.1017/CBO97811 07415324.004

Swickard, K. (2016). Academic Experience: A Handbook For The. Spring. 